\title{
Study on stability of polypropylene fibre concrete in water and abnormally high temperature
}

\begin{abstract}
Using method of immersing samples of polypropylene fibre reinforced concrete in water many days or heating them in oven, this study evaluates the water stability and abnormally high temperature stability of polypropylene fibre reinforced concrete through compressive strength index. The results indicate that the water stability of polypropylene fibre reinforced concrete is good as that of normal concrete. There is hardly any adverse effect on the stability as well as the development of concrete strength with prolonged water immersion, while the abnormally high temperatures effects significantly on the strength of concrete. However, when temperature lowers than $2500 \mathrm{C}$ with a heated duration less than 3 hours, the influence degree on compressive strength of concrete is still in permissible limits.
\end{abstract}

Volume 3 Issue 3 - 2017

\author{
Dang Van Thanh \\ Vietnam National University of Forestry,Vietnam
}

Correspondence: Dang Van Thanh, Vietnam National University of Forestry, Hanoi,Vietnam,

Email thanh40e@yahoo.com

Received: June 22, 2017| Published: August 28, 2017

Keywords: abnormally high temperature stability, fibre concrete, polypropylene fibre, water stability

\section{Introduction}

So far, there have been many studies on fibre reinforced concrete in the world with reinforced fibre types such as steel fibre, glass fibre, mineral fibre, lignin fibre, polyester fibre. These researchers have mainly concentrated on the effect of fibre to concrete, the selection of suitable fibre and the determination of optimal fibre content. Jongsung Sim \& Cheolwoo Park ${ }^{1}$ studied on basalt fibre reinforced concrete indicated that the tensile strength of basalt fibre reinforced concrete increases 1.5 to 2 times with elongation capacity raised 4-6 times as much as that of normal concrete. Dias DP \& Thaumaturgo $C^{2}$ showed that when concrete reinforced by basalt fibre with content of $2.65 \mathrm{~kg} /$ $\mathrm{m} 3$ compressive strength, fracture tensile strength and bending tensile strength would increase by $26.4 \%$ and $12 \%$, and $45.8 \%$, respectively, compared to those of normal concrete. Some of the researches in Chinese: Cui Zifeng \& Wang $\mathrm{Wei}^{3}$ the effect of polyesters fibre to compressive strength and crack resistance of concrete is more clearly than the effect of glass fibre; Shi Guogang et al. ${ }^{4}$ Basalt fibre have great impact in improving the properties of concrete, proposed fibre content should be $0.2 \%-0.3 \%$ by volume of mixture; Zheng $\mathrm{Jie}^{5}$ when basalt fibre content of $0 \%, 0.1 \%, 0.2 \%$ and $0.3 \%$ were used in concrete with B30 grade, the compressive strength at 28 days increases with the increase of the proportion of the fibre and the maximum increase of the strength was $31.5 \%$; however, the strength only increases slightly in concrete with B50 grade when the fibre content increases; Lu Chang \& Wu Zhaoxian ${ }^{6,7}$ when fibre content increases, the properties of concrete increases accordingly with the compressive strength and fracture tensile strength being the most sensitive to the increase. In Vietnam, there have also been some studies in this field: Doan Thi $\mathrm{Thu}^{8}$ carried out investigation on improving the performances of Jute/ Polypropylene composite; Nguyen Hung Phong ${ }^{9}$ studied on enhancing shear strength for concrete beam using glass fibre; Dang Van Thanh ${ }^{10}$ studied on the effect of fibre to the properties of Stone matrix Asphalt.
By reviewing the previous researches mentioned above, it can be concluded that experimental methods were helpful for the studies of fibre reinforced concrete. However, the number of experiments and the systematic methodologies were still limited. There have been few researches on Polypropylene fibre and has not published on the stability of polypropylene fibre reinforced concrete at abnormally high temperature and water. Therefore, this paper focuses into stability of polypropylene fibre concrete in water and abnormally high temperature.

\section{Materials and methods}

\section{Materials}

Binder: Portland cement PCB-40 manufactured in Vietnam was used. The technical properties of the cement are in accordance with Vietnam standard TCVN 2682:2009 ${ }^{11}$ and are shown in Table 1.

Table I Typical properties of cement PCB-40

\begin{tabular}{lll}
\hline No & Typical properties & Request \\
\hline I & Compressive strength & \\
& -3 days ( \pm 45 minutes) & $\geq 21 \mathrm{~N} / \mathrm{mm}^{2}$ \\
& -28 days ( \pm 8 hours) & $\geq 40 \mathrm{~N} / \mathrm{mm} 2$ \\
$2 \quad$ & Setting time & $\geq 45 \mathrm{mins}$ \\
& - Initial & \\
& - Final & $\leq 375 \mathrm{mins}$ \\
3 & Fineness & $\leq 10 \%$ \\
& - The amount of $0,09 \mathrm{~mm}$ sieve & \\
& - Blain rate & $\geq 2800 \mathrm{~cm} 2 / \mathrm{g}$ \\
\hline
\end{tabular}


Aggregate: Fine aggregate used for this study is sand in Red river; the sand was locally available in Sontay district, Hanoi city, Vietnam. Coarse aggregate is produced from local sources at Hoathach area, Quocoai district, Hanoi city, Vietnam. Technical properties of fine and coarse aggregates are in accordance with Vietnam Standard. ${ }^{12}$ Water: water used for mixing the concrete is as per the recommendation in Vietnam Standard. ${ }^{13}$ Fibre: The used fibre is Polypropylene. Picture of the polypropylene fibre is shown in Figure 1, and its properties are shown in Table 2.

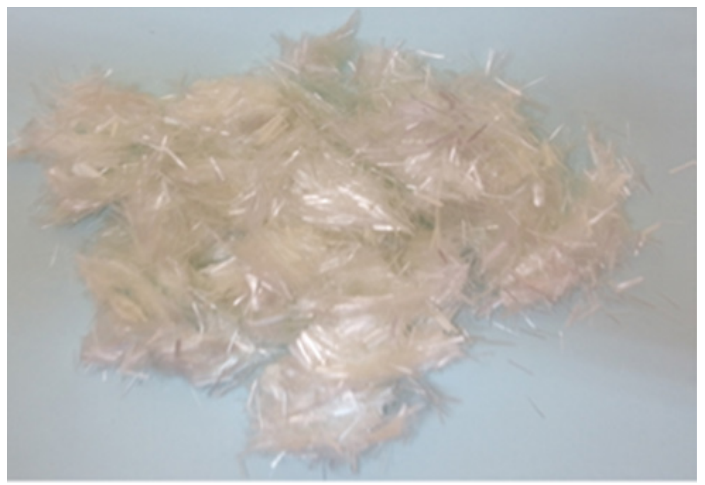

Figure I Polypropylene fibre.

Table 2 Properties of Polypropylene fibre

\begin{tabular}{ll}
\hline Properties & Value \\
\hline Density & $0,91 \mathrm{~g} / \mathrm{cm} 3$ \\
Ultimate elongation & $15 \%$ \\
Diameter & $18 \div 48 \mu \mathrm{m}$ \\
Fiber length & $6 \div 19 \mathrm{~mm}$ \\
Melting point & $160 \div 1700$ \\
Tensile strength & $\geq 460 \mathrm{MPa}$ \\
Resistance to acid and base & Good \\
Young's modulus & $\geq 3,5 \mathrm{GPa}$ \\
Water absorption & $\mathrm{N} / \mathrm{a}$ \\
Health risk & Safe, non-toxic \\
\hline
\end{tabular}

\section{Test program}

Using normal concrete samples and fibre reinforced concrete samples. After curing times of 28 days, the samples are soaked in water for 48 days or put into drying cabinet at temperature range of $2200 \mathrm{C}$ to $2500 \mathrm{C}$ for 3 hours. Through the experimented results with respect to compression strength of these samples as a well as the control samples, analyzing and evaluating the stability of polypropylene fibre concrete in water and at abnormally high temperature.

\section{Concrete mixture selection}

Selecting the composition of polypropylene fibre reinforced concrete is based on the theoretical calculation method combination with experimental method Pham Duy Huu. ${ }^{14}$ Taking the B15 level concrete is the design objectives, the material components containing stone (D), sand (S), cement (C), water (W) and polypropylene fibre (P) are shown in the Table 3.
Table 3 Selecting composition of polypropylene fibre concrete

\begin{tabular}{llll}
\hline $\mathbf{S}\left(\mathrm{kg} / \mathrm{m}^{3}\right)$ & $\mathbf{C}\left(\mathrm{kg} / \mathrm{m}^{3}\right)$ & $\mathbf{W}\left(1 / \mathrm{m}^{3}\right)$ & $\mathbf{P ( \mathrm { kg } / \mathrm { m } ^ { 3 } )}$ \\
\hline 747 & 300 & 210 & 1.6 \\
\hline
\end{tabular}

\section{Compressive strength test}

The determination of the strength of concrete is performed according to Vietnam standards using concrete samples in cube shape with size $15 \times 15 \times 15 \mathrm{~cm}$. The hydraulic press machine used for determining concrete strength is shown in Figure 2.

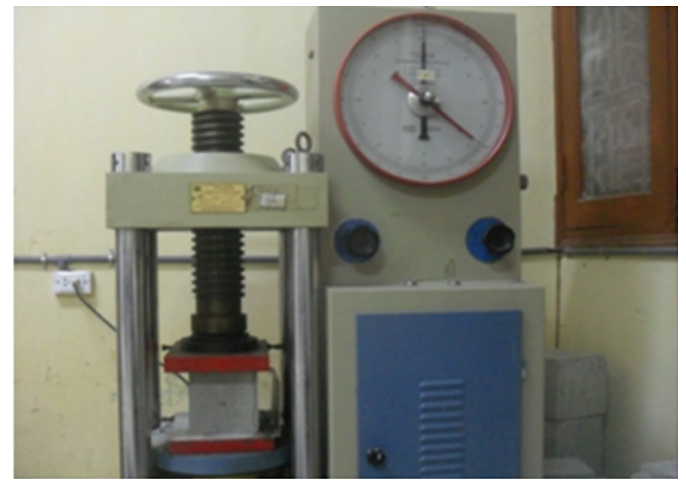

Figure 2 Hydraulic press machine for determining concrete strength.

\section{Results and discussion}

\section{Water stability test}

The experimental results of compressive strength of polypropylene fibre reinforced concrete samples soaked additionally in 48-day duration and the control samples are shown in Table 4 \& Figure 3. Compressive strength of samples additionally soaked in 48-day duration and control samples. The experimental results from Table 4 \& Figure 3 shows that: After being additionally soaked in 48day duration the compressive strength of concrete samples were not significant change comparing to that of the same type concrete samples that are not additionally soaked. This can be explained that concrete is a material whose strength increases with time. This increasement is rapid in the early period and slows down afterward and it almost increases according to the logarithmic rules. Furthermore, due to structure characteristics of the material components, water is a favourable environment for the development of concrete strength. Therefore, after being cured in standard conditions within 28-day duration, the additional soak of concrete samples in 48-day period leads to inevitable increasement of strength. ${ }^{15}$

Table 4 Experiment results of water stability

\begin{tabular}{lllll}
\hline & Sample I & Sample 2 & Sample 3 & Average \\
\hline Rbfl (MPa) & 23.5 & 24 & 23.8 & 23.77 \\
RbI (MPa) & 22.6 & 23.7 & 22.3 & 22.87 \\
Rbf2 (MPa) & 23.5 & 24.5 & 24.3 & 24.1 \\
Rb2 (MPa) & 22.8 & 23.14 & 23.5 & 23.15 \\
\hline
\end{tabular}

Notes: $R_{b f f}, R_{b 1}$-the compressive strength of fibre concrete and normal concrete samples soaked additionally in 48-day duration; $R_{b p}, R_{b 2}$-the compressive strength of fibre concrete and normal concrete samples that are not additionally soaked. 


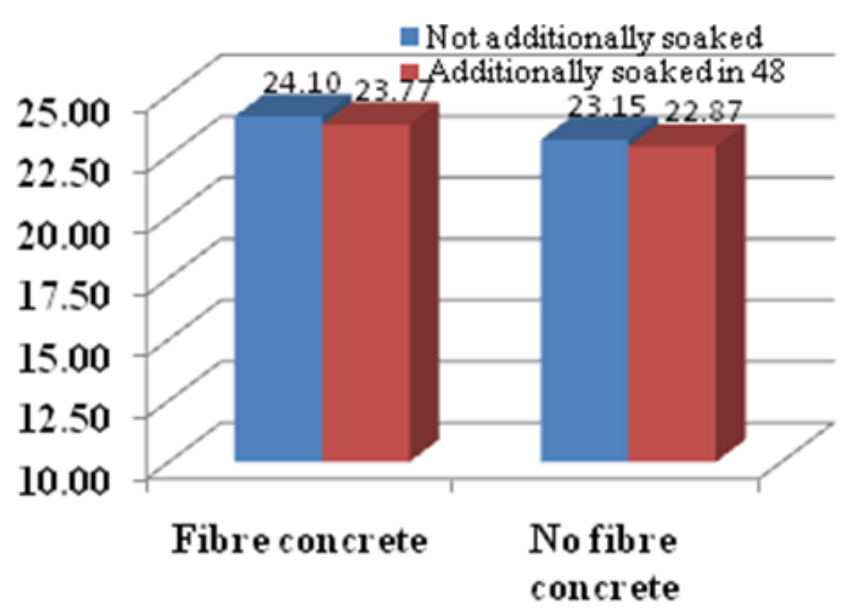

Figure 3 Compressive strength of samples additionally soaked in 48-day duration and control samples.

Water stability of fibre concrete and normal concrete can be evaluated via stable coefficient $\left(\mathrm{K}_{\mathrm{w}}\right)$ as follows:

$$
K_{\mathrm{wf}}=\frac{R_{b f 1}}{R_{b f 2}}=\frac{23.77}{24.1}=0.986 K_{\mathrm{w}}=\frac{R_{b 1}}{R_{b 2}}=\frac{22.87}{23.15}=0.988
$$

Where: $\mathrm{K}_{\mathrm{wf}}$

- water stability coefficient of fibre concrete; $\mathrm{K}_{\mathrm{w}}$
- water stability coefficient of normal concrete.

From the water stability coefficient, it shows that, as well as normal concrete, the water stability of polypropylene fibre reinforced concrete is very good.

\section{Abnormally high temperature stability test}

Experimental results about the compressive strength of the fibre concrete samples and the control samples that are heated at temperature of $220^{\circ} \mathrm{C}$ to $250^{\circ} \mathrm{C}$ in 3-hour duration are shown in Table $5 \&$ Figure 4 . The experimental results in Table $5 \&$ Figure 4 show that after being heated at $220^{\circ} \mathrm{C}$ to $250^{\circ} \mathrm{C}$ in 3-hour duration, the compressive strength of concrete samples are reduced comparing to that of the same type of concrete samples at 28-day age. This can be explained that, as well as many other materials, the high temperature environment is not a normal working environment of concrete. Because of increasement temperature, the split of free water and bound water in cement stone makes cement stone shrink. This leads to destruction of the concrete structure; the higher the temperature is, the faster the speed of destruction is. The destruction is especially serious if the time suffering from high temperature lasts long. When the affected time of high temperature is short, due to in high temperature, the outermost layer of concrete structure is destroyed and creates a porous membrane having effect of insulation making the heat transmits inside structure slowly; but if the affected time is longer, the influence spreads into deeply concrete structure and cement stone destroying the linkage of cement and stone, this leads to strength of concrete reduces.

Table 5 Experiment results at abnormally high temperature stability.

\begin{tabular}{llllll}
\hline \multirow{2}{*}{ Symbol samples } & \multicolumn{4}{l}{ Strength of the samples heated in 3 duration-Rb3h (MPa) } & Rb28 (MPa) \\
\cline { 2 - 6 } & Sample I & Sample 2 & Sample 3 & Average & \\
\hline Ms & 19.3 & 20.3 & 20.6 & 20.1 & 23 \\
M & 20.5 & 20.7 & 19.9 & 20.4 & 21.8 \\
\hline
\end{tabular}

Notes: Ms, M, concrete samples with and without the using fibre reinforced; Rb28, compressive strength of concrete samples at 28 days; Rb3h, compressive strength of concrete samples heated after 3 hours at a temperature of $220^{\circ} \mathrm{C}$ to $250^{\circ} \mathrm{C}$

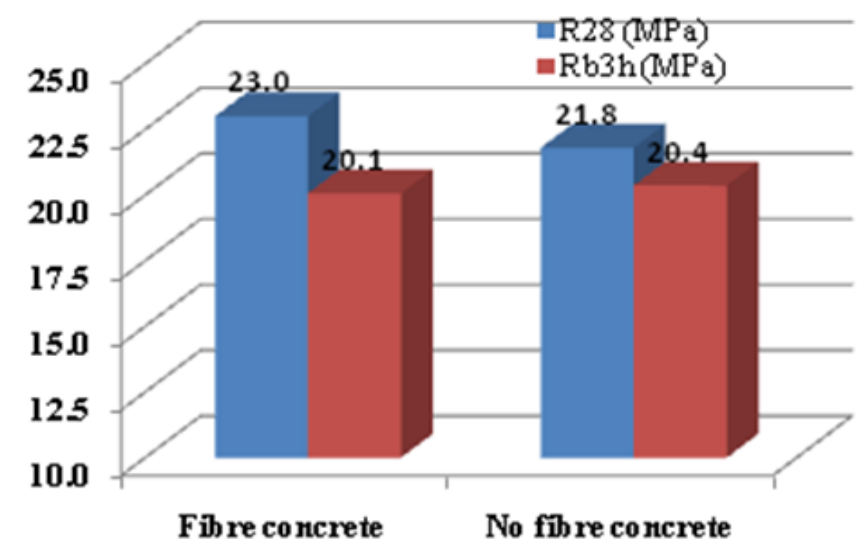

Figure 4 Compressive strength of the samples heated in 3-hour duration and control samples.

The experimental results show that when in high temperature, compressive strength of normal concrete decreases with smaller rate comparing to decrease of fibre concrete samples: the compressive strength of concrete samples without fibre reduces from $21.8 \mathrm{MPa}$ to $20.4 \mathrm{MPa}$ (down $6.57 \%$ ); while the compressive strength of fibre reinforced concrete samples reduced from $23.0 \mathrm{MPa}$ to $20.1 \mathrm{MPa}$ (down 12.75\%). This distinct difference can be explained that: heat resistance of Polypropylene fibre is less with the melting temperature about of $160^{\circ} \mathrm{C}$ to $170^{\circ} \mathrm{C}$ (Table 2). Therefore, when temperature increasing highly in long duration makes fibre melt, broken down then it makes not only the effect of fibre reinforcement lose, but also creates small empty spaces (due to melted fibres given) mixing and widely distributing within the concrete; at a certain level, these empty spaces would decrease the compressive strength of overall concrete samples; however, due to the less fibre content used, the empty spaces in concrete are not much so that the degree of influence is also less. The results in Table 5 shows that: the average strength of concrete samples using fibre reinforced heated in 3-hour duration are also approximately the average strength of concrete samples without fibre and both of them are satisfied the requirement strength (20MPa).

From the experimental results and analyzes above, we can recognize that the impact degree of the abnormally high temperature to strength of fibre reinforced concrete is larger than that of normal concrete; however, at temperatures is not exceeding $2500 \mathrm{C}$ and time under high temperature is not exceeding 3 hours, level of influence is also not very great, compressive strength of concrete still ensures the 
requirements. Abnormally high temperature stability of fibre concrete and normal concrete can be evaluated via stable coefficient (KT) as follows:

$$
K_{T f}=\frac{R_{b 3 h}}{R_{28}}=\frac{20.1}{23.0}=0.87 \quad K_{T}=\frac{R_{b 3 h}}{R_{28}}=\frac{20.4}{21.8}=0.93
$$

Where: $\mathrm{K}_{\mathrm{Tf}}$-stability coefficient at abnormally high temperature of fibre concrete; $\mathrm{K}_{\mathrm{T}}$-stability coefficient at abnormally high temperature of normal concrete.

Through the stability coefficient shows that the stability at abnormally high temperature of fibre concrete is less than that of normal concrete.

\section{Conclusion}

Using method of laboratory experiments, the samples are immersed in water and heated in the oven, through compressive strength index, initially it can give some conclusions about the stability of concrete using polypropylene fibre at abnormally high temperature and in water as follows:

1. The compressive strength of the concrete samples after being soaked additionally in water in 48-day duration are not significant change from the same type concrete samples that are not additionally soaked; through the water stability coefficient shows that: as well as normal concrete, the water stability of polypropylene fibre reinforced concrete is very good.

2. The compressive strength of the concrete samples using polypropylene fibre after being heated at $2200 \mathrm{C}$ to $2500 \mathrm{C}$ in 3 -hour duration are less than that of the same type of concrete samples at 28-day age; however, the reducing level of the fibre concrete is greater than that of normal concrete; when temperatures is not exceeding $2500 \mathrm{C}$ and high temperature time is not exceeding 3 hours, level of influence is also not very great, compressive strength of concrete is still in allowable limit. Through the stability coefficient shows that the stability at abnormally high temperature of fibre concrete is less than that of normal concrete.

\section{Acknowledgments}

None.

\section{Funding}

None.

\section{Conflicts of interest}

None.

\section{References}

1. Jongsung Sim, Cheolwoo Park. Characteristics of basalt fiber as a strengthening material for concrete structures. Department of Civil and Environmental Engineering, Hanyang University, South Korea: Sa-1dong, Ansan, Kyunggi; 2006. p. 425-791.

2. Dias DP, Thaumaturgo C. Fracture toughness of geopolymeric concretes reinforced with basalt fibers. $J$ Cement and Concrete Composites. 2005;27:49-54.

3. Cui Zifeng, Wang Wei. Study glass fiber and polyester fiber mechanical properties of concrete. J Construction Technolog. 2010;5:0151-0153.

4. Shi Guogang, Li Haitao, Xing-Yu Gu. Flexible basalt fiber cement concrete mix design optimization. J Highway and Transportation Research. 2012;5:24-29.

5. Zheng Jie. Study on effect of basalt fiber in concrete. J China \& Foreign Highway. 2011;5:0243-0246.

6. Lu Chang. Study on Performance and Application of Basalt Fiber Reinforced Concrete Pavement. China: Henan University; 2012.

7. Wu Zhaoxian. Mechanical properties and application of basic basalt fiber reinforced concrete. China: Wuhan University of Technology; 2009. 4 p.

8. Đoan Thi Thu Loan. Study to improve features of composite materials of jute/polypropylene plastic using basic plastic modification method. Journal of Science and Technology. 2010;28-35.

9. Nguyen Hung Phong. Experimental study of shear reinforcement for reinforced concrete beams using fiberglass panels. Journal of Science and Technology in Civil Engineering. 2014;3(6):9-19.

10. Dang Van Thanh. Study on factors affecting the high temperature stability of SMA and the roles of fiber on this stability. Northeast Forestry University. 2013;602:1014-1020.

11. TCVN 2682. Portland cements-Specifications. Vietnam: Vietnam Standard; 2009.

12. TCVN 7570. Aggregates for concrete and mortar-Specifications. Vietnam: Vietnam Standard; 2006.

13. TCXDVN 302. Water for mixing concrete and mortar-Technical Specification. Vietnam Standard; 2004.

14. Pham Duy Huu. Building materials. Vietnam: Communications Press, Hanoi; 2011.

15. TCVN 3118. Heavyweight concrete-Method for determination of compressive strength. Vietnam: Vietnam Standard; Hanoi; 1993. 